\title{
ADVERSE DRUG REACTIONS AMONG DRUG-RESISTANT TUBERCULOSIS TREATMENT: AN OBSERVATIONAL COHORT STUDY
}

\author{
LEYA P. BABU ${ }^{1}$, NIMMY ROBIN ${ }^{1}$, JOHNSON V. BABU ${ }^{1}$, JOICY JOSE ${ }^{1}$, SHAJI GEORGE ${ }^{2}$
}

1Pharm. D Interns. Nirmala College of Pharmacy, Muvattupuzha, Kerala 686661, ²Department of Pharmacy Practice, Nirmala College of Pharmacy, Muvattupuzha, Kerala 686661

Email: shajige@gmail.com

Received: 17 Jun 2021, Revised and Accepted: 28 Jul 2021

ABSTRACT

Objective: Adverse drug reaction (ADR) is regarded as one of the major challenges in the treatment of drug-resistant tuberculosis (DR-TB). It can lead to non-compliance or interrupting treatment completion, which can contribute to avoidable morbidity, drug resistance, treatment failure, reduced quality of life, or mortality.

Methods: A retrospective cohort study was conducted in the Ernakulam district of Kerala from 2016 to 2019. All DR-TB patients registered under the DR-TB center were enrolled in the study. Due to privacy and confidentiality HIV infected patients and patients below 12 y of age were excluded in this study and only the data with ADR reported by patients is collected from medical records.

Results: Out of the total 146 patients, about $75 \%$ of patients experienced at least one ADR during treatment, and a total of 208 ADRs were reported. Among all the ADRs, the most common ADR was gastritis (12.98\%) followed by ototoxicity (10\%) and vomiting (5.76\%), etc. It was found that males (78.76\%) within the age group 46-65 y exhibited more ADR than females. Some of the ADR requires drug withdrawal and replacement with other drugs and most of the patients also needed symptomatic treatment without modifying the treatment regimen. All ADR reported were collected and causality assessment was done via WHO and Naranjo scale. The majority of ADR belongs to the "probable" category in the WHO scale and Naranjo scale. The evaluation of the severity of ADR by using the Modified Hartwig and Siegel scale indicated that most of the ADR was of moderate level showing a $4 \mathrm{~b}$ reaction. The study also assessed the preventability of ADR using the Schumock and Thornton preventability scale.

Conclusion: Many of the ADRs were unidentified or not reported due to several reasons like milder ADR, patient lack of knowledge, Negligence of symptoms, unawareness of health providers, etc. Whereas the long-term treatment and diversities in age, gender, etc. were found as major contributors to ADR along with comorbidities. New drugs in combination with existing drugs created the potential for previously unnotified reactions. Pharmacovigilance should address the safety of therapy and identify ADRs, especially the serious ones with routine monitoring to prevent mortality, morbidity, and other negative outcomes.

Keywords: Adverse drug reaction, Drug resistance TB, Causality assessment, Severity assessment

(C) 2021 The Authors. Published by Innovare Academic Sciences Pvt Ltd. This is an open access article under the CC BY license (https://creativecommons.org/licenses/by/4.0/) DOI: https://dx.doi.org/10.22159/ijpps.2021v13i9.42460. Journal homepage: https://innovareacademics.in/journals/index.php/ijpps.

\section{INTRODUCTION}

Tuberculosis, an infectious disease caused by Mycobacterium tuberculosis with inappropriate treatment can increase the risk of treatment failure, relapse, and drug resistance [1]. Drug resistance TB(DR-TB) is an alarming obstacle to effective TB treatment and prevention [2] and it occurs when the bacteria become resistant to at least isoniazid and rifampicin, the two most powerful anti-TB drugs. A rare type of DR-TB observed is called, extensively drugresistant TB (XDR-TB) which is resistant to isoniazid, rifampicin, any fluoroquinolones, and at least one of three second-line injectable drugs (i.e., kanamycin, capreomycin, amikacin) [3].

Drug susceptible TB is treated with regimens containing first-line drugs (FLDs') whereas treatment of DR-TB requires a regimen comprising both second-line drugs (SLDs'), a few FLDs', some add on agents (Bedaquiline and Delamanid) [4] and thus is associated with an increased incidence of adverse drug reactions (ADR). The incidence of ADR during treatment may vary from $5 \%$ to $52 \%$ [5]. The drug-resistant strain requires a prolonged duration of therapy with second-line drugs which are highly toxic and less effective, as a result, adverse drug reactions are very common during treatment [6]. The severity of the reaction can range from mild which does not require immediate modification of standardized regimen and it can be continued with the help of a supportive drug to the more severe or life-threatening condition where alteration or even discontinuation of the treatment is required [7]. ADRs were determined by clinical criteria or laboratory data documented in the patient chart [8]. The following lab parameters have to be investigated such as renal function test, Liver function test,
Thyroid function test, Complete blood count, and Audiometry every three months during treatment to define the ADR [6]

ADR is regarded as one of the major causes of patient noncompliance to the treatment and there may be a higher risk of treatment failure and default, finally affecting outcome [9]. If the ADR is not properly monitored, it becomes irreversible resulting in disability or permanent damage, therefore it is imperative to monitor and treat the ADR in a systemic and timely manner [6]. To attain better patient compliance and to boost the treatment results, documentation of drug events is necessary along with its assessment and management [8]. This study aims to monitor the occurrence of adverse drug reactions in patients of DR-TB and to assess the causality, severity, and preventability of reported adverse drug reactions.

\section{MATERIALS AND METHODS}

\section{Study design and setting}

A multi-center retrospective cohort study was undertaken at Ernakulam district, Kerala from 2016 to 2019 among DR-TB patients. All the DR-TB patients registered under the district tuberculosis center (DTC), Ernakulam (which includes 8 TB units with 16-18 subunits) were enrolled in the study. The study involves a detailed evaluation of patient records for ADR maintained by the Revised National Tuberculosis Control Programme (RNTCP) in the government sector and the medical records were sorted and selected according to the inclusion and exclusion criteria. The inclusion criteria were the patients registered under RNTCP in Ernakulam district from 2016-2019 with an age greater than 12 y 
and the study excluded patients with HIV, as access to DR-TB patients with HIV, was denied due to sensitive social data.

\section{Data collection}

The retrospectively collected data were extracted from medical records of DR-TB patients, and as it involved only the reviewing of treatment files, informed consent was not mandatory. All reported ADR were documented in a digital sheet (Excel 2016) which consisted of age, sex, comorbidity, duration, causative agent, and treatment. The ADRs that were not defined by a laboratory test, the physician documented in patient chart based on clinical expertise and patient-reported signs or symptoms. All medical records were treated with complete confidentiality.

\section{Data analysis}

The data were analysed using SPSS 25 and G Power 3.1.9.2. Descriptive statistics like frequency and percent were used to summarize the data.

Severity assessment of ADRs was done by using the Modified Scale of Hartwig and Siegel into the mild, moderate, and severe categories.
Causality assessment of adverse drug reaction was obtained with WHO-UMC criteria and Naranjo's causality algorithm. Also assessed the preventability using Modified Schumock and Thornton scale.

\section{Ethics}

The scientific committee granted the conductance of the study and Ethical approval was obtained from the Institutional Human Ethics Committee (IHEC) via no: 012/IHEC/10/2019/NCP. Permission to conduct this study was additionally sought from the State and District TB office after submitting the IHEC approval with the proposed plan. Later OR committee and Directorate of Health Science solemnly approved the study with clearance No: 281/STC/DHS/2019.

\section{RESULTS}

A total of 146 participants who were on treatment during 20162019 were enrolled in this study. Among 146 DR-TB patients,115 (78.76\%) were males and $31(21.23 \%)$ were females. Most of the study participants (47.9\%) were in the age group of 46-65 y followed by $30.8 \%$ in the age group of $26-45$ y (fig. 1).

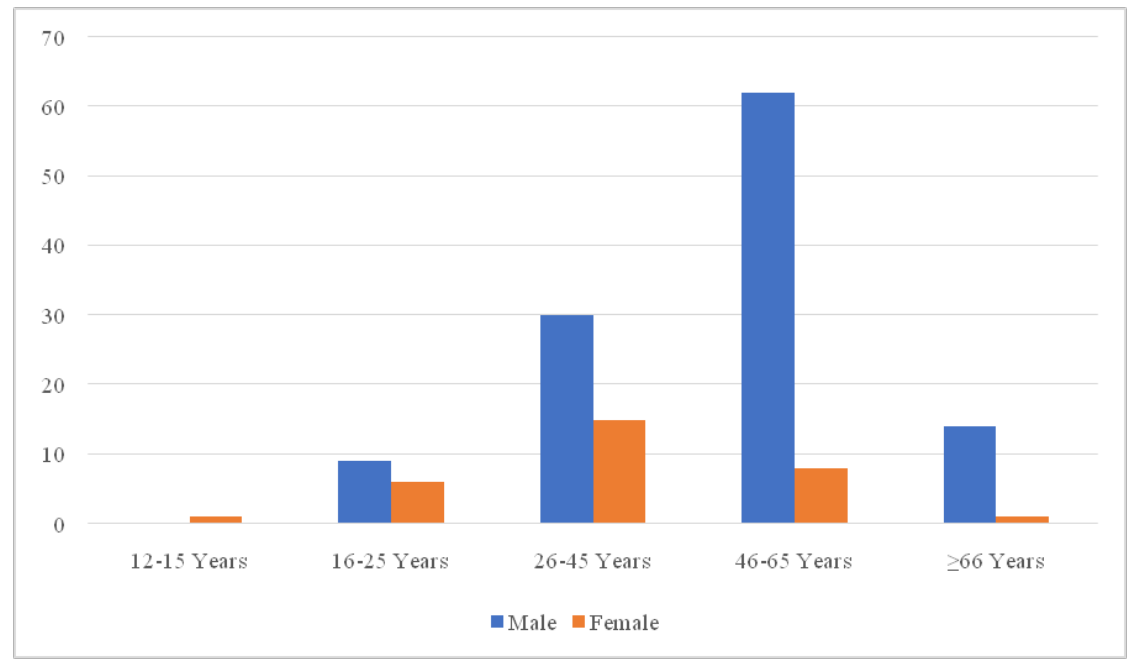

Fig. 1: Distribution of DR-TB patients according to sex and age

Out of 146 patients, 91 patients have experienced about 208 adverse drug reactions of various types and there were many more ADRs that caused a change in lab data of individual patients, among which the most prevalent ones are included in table 1. Among all the ADRs extracted the most common ADR was found to be gastritis (12.98\%), ototoxicity (10\%), vomiting (5.76\%), QT prolongation $(4.8 \%)$, anemia $(4.32 \%)$, insomnia $(4.32 \%)$, joint pain $(3.84 \%)$, nephrotoxicity $(3.36 \%)$, psychosis $(2.88 \%)$ and hypothyroidism $(2.88 \%)$. It was found that males $(82.69 \%)$ experienced higher ADR than females $(17.30 \%)$ which might be due to higher male participants.

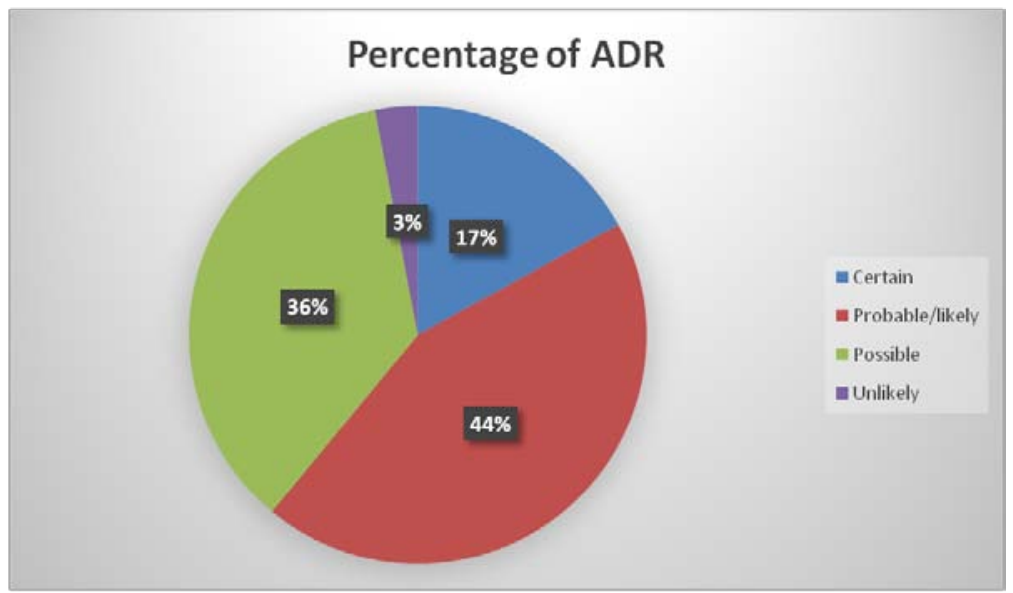

Fig. 2: WHO-UMC causality assessment, On doing severity assessment of ADR by using modified hartwig and seigel scale, $23.07 \%$ were moderate reaction (level $4 \mathrm{~b}$ ) and $17.3 \%$ were mild category (level 2 ) 
Table 1: Frequency of adverse drug reaction

\begin{tabular}{|c|c|c|c|}
\hline ADR & Male & Female & Total \\
\hline Abdominal discomfort & $2(100 \%)$ & 0 & $2(0.96 \%)$ \\
\hline Abnormal ECG & 0 & $1(100 \%)$ & $1(0.48 \%)$ \\
\hline Acute kidney injury & $4(80 \%)$ & $1(20 \%)$ & $5(2.40 \%)$ \\
\hline Anaemia & $5(55.5 \%)$ & $4(44.4 \%)$ & $9(4.32 \%)$ \\
\hline Anisopoikilocytosis & $1(100 \%)$ & 0 & $1(0.48 \%)$ \\
\hline Anxiety & $2(100 \%)$ & 0 & $2(0.96 \%)$ \\
\hline Arrhythmia & $1(100 \%)$ & 0 & $1(0.48 \%)$ \\
\hline Arthralgia & $3(75 \%)$ & $1(25 \%)$ & $4(1.92 \%)$ \\
\hline Arthritis & $3(100 \%)$ & 0 & $3(1.44 \%)$ \\
\hline Bleeding & $1(100 \%)$ & 0 & $1(0.48 \%)$ \\
\hline Blurred vision & $4(100 \%)$ & 0 & $4(1.92 \%)$ \\
\hline Breathing difficulty & $2(100 \%)$ & 0 & $2(0.96 \%)$ \\
\hline Cystitis & $1(100 \%)$ & 0 & $1(0.48 \%)$ \\
\hline Depression & $1(100 \%)$ & 0 & $1(0.48 \%)$ \\
\hline Gall stone & $1(100 \%)$ & 0 & $1(0.48 \%)$ \\
\hline Gastritis & $23(85.1 \%)$ & $4(14.8 \%)$ & $27(12.98 \%)$ \\
\hline Giddiness & $5(100 \%)$ & 0 & $5(2.40 \%)$ \\
\hline Gynaecomastia & $1(100 \%)$ & 0 & $1(0.48 \%)$ \\
\hline Hallucination & $2(100 \%)$ & 0 & $2(0.96 \%)$ \\
\hline Hematologic abnormality & 0 & $1(100 \%)$ & $1(0.48 \%)$ \\
\hline Hyperuricemia & $3(60 \%)$ & $2(40 \%)$ & $5(2.40 \%)$ \\
\hline Hyperglycaemia & $1(100 \%)$ & 0 & $1(0.48 \%)$ \\
\hline Hyperkalaemia & $1(100 \%)$ & 0 & $1(0.48 \%)$ \\
\hline Hyperpigmentation & $1(100 \%)$ & 0 & $1(0.48 \%)$ \\
\hline Hyponatremia & $3(100 \%)$ & 0 & $3(1.44 \%)$ \\
\hline Hypoproteinaemia & $1(100 \%)$ & 0 & $1(0.48 \%)$ \\
\hline Hypotension & 0 & $1(100 \%)$ & $1(0.48 \%)$ \\
\hline Hypothyroidism & $4(66.6 \%)$ & $2(33.33 \%)$ & $6(2.88 \%)$ \\
\hline Insomnia & $8(88.8 \%)$ & $1(11.11 \%)$ & $9(4.32 \%)$ \\
\hline Itching & $3(75 \%)$ & $1(25 \%)$ & $4(1.92 \%)$ \\
\hline Joint pain & $7(87.5 \%)$ & $1(12.5 \%)$ & $8(3.84 \%)$ \\
\hline LFT elevation & $3(100 \%)$ & 0 & $3(1.44 \%)$ \\
\hline Mood swings & $1(100 \%)$ & 0 & $1(0.48 \%)$ \\
\hline Nausea & $4(100 \%)$ & 0 & $4(1.92 \%)$ \\
\hline Nephrotoxicity & $6(85.71 \%)$ & $1(14.28 \%)$ & $7(3.36 \%)$ \\
\hline Numbness & $2(100 \%)$ & 0 & $2(0.96 \%)$ \\
\hline Optic neuropathy & $1(100 \%)$ & 0 & $1(0.48 \%)$ \\
\hline Ototoxicity & $18(85.71 \%)$ & $3(14.28 \%)$ & $21(10 \%)$ \\
\hline Paraesthesia & $1(100 \%)$ & 0 & $1(0.48 \%)$ \\
\hline Pedal oedema & $2(100 \%)$ & 0 & $2(0.96 \%)$ \\
\hline Peripheral neuropathy & $4(100 \%)$ & 0 & $4(1.92 \%)$ \\
\hline Photosensitivity & $1(100 \%)$ & 0 & $1(0.48 \%)$ \\
\hline Psychosis & $3(50 \%)$ & $3(50 \%)$ & $6(2.88 \%)$ \\
\hline QT prolongation & $10(100 \%)$ & 0 & $10(4.8 \%)$ \\
\hline Sinus tachycardia & 0 & $2(100 \%)$ & $2(0.96 \%)$ \\
\hline Throat congested & $1(100 \%)$ & 0 & $1(0.48 \%)$ \\
\hline Tiredness/weakness & $3(60 \%)$ & $2(40 \%)$ & $5(2.4 \%)$ \\
\hline Tremor & $1(100 \%)$ & 0 & $1(0.48 \%)$ \\
\hline UTI & $1(50 \%)$ & $1(50 \%)$ & $2(0.96 \%)$ \\
\hline Vertigo & $5(83.33 \%)$ & $1(16.66 \%)$ & $6(2.88 \%)$ \\
\hline Vomiting & $9(75 \%)$ & $3(25 \%)$ & $12(5.76 \%)$ \\
\hline Watery eyes & $1(100 \%)$ & 0 & $1(0.48 \%)$ \\
\hline Xeroderma & $1(100 \%)$ & 0 & $1(0.48 \%)$ \\
\hline Total & $172(82.69 \%)$ & $36(17.30 \%)$ & 208 \\
\hline
\end{tabular}

The main action taken in patients detected with ADR was to withhold, stop, continue, or replace the culprit drug and provide supportive treatment. Gastrointestinal manifestations are frequently observed with all the DR-TB regimens. The most common causative agents are Kanamycin (24.03\%) followed by cycloserine (Cs) $(8.17 \%)$ and ethambutol $(5.76 \%)$ (table 2). Out of 15 patients experiencing psychiatric symptoms with Cs, six patients required withdrawal and were substituted mainly with PAS.

Table 2: Drug details regarding ADR

\begin{tabular}{|c|c|c|c|c|c|c|}
\hline Drug & ADR & Withhold drug & Stop drug & Continued & Sub drug & Treatment \\
\hline \multirow[t]{3}{*}{ Isoniazid } & Hyperpigmentation (1) & 0 & 0 & 1 & 0 & Nil \\
\hline & Peripheral neuropathy (2) & 1 & 1 & 0 & 0 & Pyridoxine-1 \\
\hline & LFT elevated (1) & 0 & 0 & 1 & 0 & Silymarin, ursodeoxycholic acid-1 \\
\hline \multirow[t]{3}{*}{ Ethambutol } & Hyperuricemia (3) & 0 & 0 & 3 & 0 & Febuxostat, allopurinol-3 \\
\hline & Joint pain (1) & 0 & 0 & 1 & 0 & Febuxostat-1 \\
\hline & Insomnia (1) & 0 & 0 & 1 & 0 & Clonazepam-1 \\
\hline
\end{tabular}




\begin{tabular}{|c|c|c|c|c|c|c|}
\hline & Blurred vision (3) & 1 & 1 & 1 & 0 & Nil \\
\hline & Psychosis (1) & 0 & 0 & 1 & 0 & Olanzapine-1 \\
\hline & Watery eyes (1) & 0 & 0 & 1 & 0 & Nil \\
\hline & Optic neuropathy (1) & 0 & 1 & 0 & 0 & Nil \\
\hline & Hypothyroidism (1) & 1 & 0 & 0 & 0 & Thyronorm-1 \\
\hline \multirow[t]{3}{*}{ Pyrazinamide } & Hyperuricemia (5) & 1 & 1 & 3 & PAS-1 & Febuxostat, allopurinol-5 \\
\hline & Joint pain (5) & 0 & 0 & 4 & 0 & Febuxostat-1, tramadol-5 \\
\hline & Arthralgia (1) & 0 & 0 & 1 & 0 & Tramadol-1 \\
\hline \multirow[t]{9}{*}{ Kanamycin } & AKI (3) & 0 & 2 & 1 & PAS-3 & Nil \\
\hline & Ototoxicity (27) & 0 & 17 & 6 & PAS-14 & Birthstone, cetirizine- 5 \\
\hline & Nephrotoxicity (6) & 1 & 2 & 3 & PAS-1 & Dose adjusted-1 \\
\hline & Vertigo (6) & 0 & 6 & 0 & PAS-5 & Cetrizine, prochlorperazine \\
\hline & Giddiness (4) & 0 & 4 & 0 & PAS-3 & prochlorperazine-1 \\
\hline & Severe itching (1) & 0 & 1 & 0 & PAS-1 & Symptomatic \\
\hline & Swelling of face (1) & 0 & 1 & 0 & PAS-1 & Symptomatic \\
\hline & Neuropathic pain (1) & 0 & 1 & 0 & PAS-1 & Symptomatic \\
\hline & UTI (1) & & & & 0 & Symptomatic \\
\hline \multirow[t]{5}{*}{ Levofloxacin } & Giddiness (1) & 0 & 1 & 0 & 0 & Promethazine-1 \\
\hline & Numbness (1) & 0 & 0 & 1 & 0 & Nil \\
\hline & QT prolongation (1) & 0 & 0 & 1 & 0 & Nil \\
\hline & Arrhythmia (1) & 0 & 0 & 1 & 0 & Propanolol, aspirin-1 \\
\hline & Arthralgia (1) & 0 & 0 & 1 & 0 & Tramadol, paracetamol-1 \\
\hline \multirow[t]{2}{*}{ Moxifloxacin } & QT prolongation (5) & 0 & 0 & 5 & 0 & Nil \\
\hline & Abnormal ECG (1) & 0 & 1 & 0 & 0 & Nil \\
\hline \multirow[t]{3}{*}{ Ethionamide } & Vision problem (1) & 0 & 0 & 1 & 0 & Nil \\
\hline & Hypothyroidism (3) & 0 & 1 & 2 & PAS-1 & Thyronorm-3 \\
\hline & Gynaecomastia (1) & 0 & 1 & 0 & 0 & Pyridoxine, ranitidine-1 \\
\hline \multirow[t]{2}{*}{ Linezolid } & Peripheral neuropathy (1) & 0 & 1 & 0 & 0 & Nil \\
\hline & $\begin{array}{l}\text { Haematologicalabnormalit } \\
\text { y (1) }\end{array}$ & 1 & 0 & 0 & 0 & Supplements-1 \\
\hline \multirow[t]{7}{*}{ Cycloserine } & Psychosis(4) & 0 & 3 & 1 & PAS-1 & Counselling-1, risperidone \\
\hline & Insomnia(7) & 1 & 0 & 6 & 0 & Clonazepam-7, amitriptyline- 1 \\
\hline & Hallucination(2) & 1 & 1 & 0 & PAS-2 & Clonazepam, serenace-2 \\
\hline & Delirium(1) & 0 & 1 & 0 & PAS-1 & Sizodon, clozapine-1 \\
\hline & Paresthesia(1) & 0 & 1 & 0 & PAS-1 & Nil \\
\hline & Depression(1) & 0 & 1 & 0 & PAS-1 & Nil \\
\hline & Hypotension(1) & 0 & 1 & 0 & 0 & \\
\hline \multirow[t]{2}{*}{ Bedaquiline } & Sinus tachycardia (1) & 0 & 0 & 0 & 0 & Aspirin, Sorbitrate, \\
\hline & QT prolongation (2) & 1 & 0 & 1 & 0 & Nil \\
\hline Delamanid & QT prolongation (1) & 0 & 1 & 0 & 0 & Nil \\
\hline
\end{tabular}

AKI-acute kidney injury, UTI-Urinary tract infection, LFT-Liver function test. Causality assessment of all ADRs was done by using both Naranjo's causality assessment and the WHO-UMC scale. The assessment by Naranjo's scale revealed that $6(2.8 \%)$ adverse drug reactions were categorized as definite, $141(67.8 \%)$ as probable, and $61(29.32 \%)$ as possible reactions.

Table 3: Categorizationof ADR by naranjo's causality assessment

\begin{tabular}{ll}
\hline Causality & NO. OF ADR (\%) \\
\hline Definite & $6(2.8 \%)$ \\
Probable & $141(67.8 \%)$ \\
Possible & $61(29.32 \%)$ \\
\hline
\end{tabular}

The assessment done by using the WHO-UMC scale showed that the majority of the ADR (44\%) falls under the probable category.

Table 4: Severity assessment of ADRs by modified hartwig and seigel scale

\begin{tabular}{|c|c|c|c|}
\hline Severity & & No. of ADR & Percentage (\%) \\
\hline \multirow[t]{2}{*}{ Mild } & level 1 & 33 & 15.86 \\
\hline & Level 2 & 36 & 17.30 \\
\hline \multirow[t]{3}{*}{ Moderate } & Level 3 & 24 & 11.53 \\
\hline & Level $4 \mathrm{a}$ & 19 & 9.13 \\
\hline & Level 4 b & 48 & 23.07 \\
\hline \multirow[t]{3}{*}{ Severe } & Level 5 & 3 & 1.44 \\
\hline & Level 6 & 33 & 15.9 \\
\hline & Level 7 & 12 & 5.76 \\
\hline
\end{tabular}

Preventability assessment was based on Schumock and Thronton scale and showed that the majority ( $32.2 \%)$ were not preventable while only 2 (0.96\%) were definitely preventable ADRs (fig. 3). 


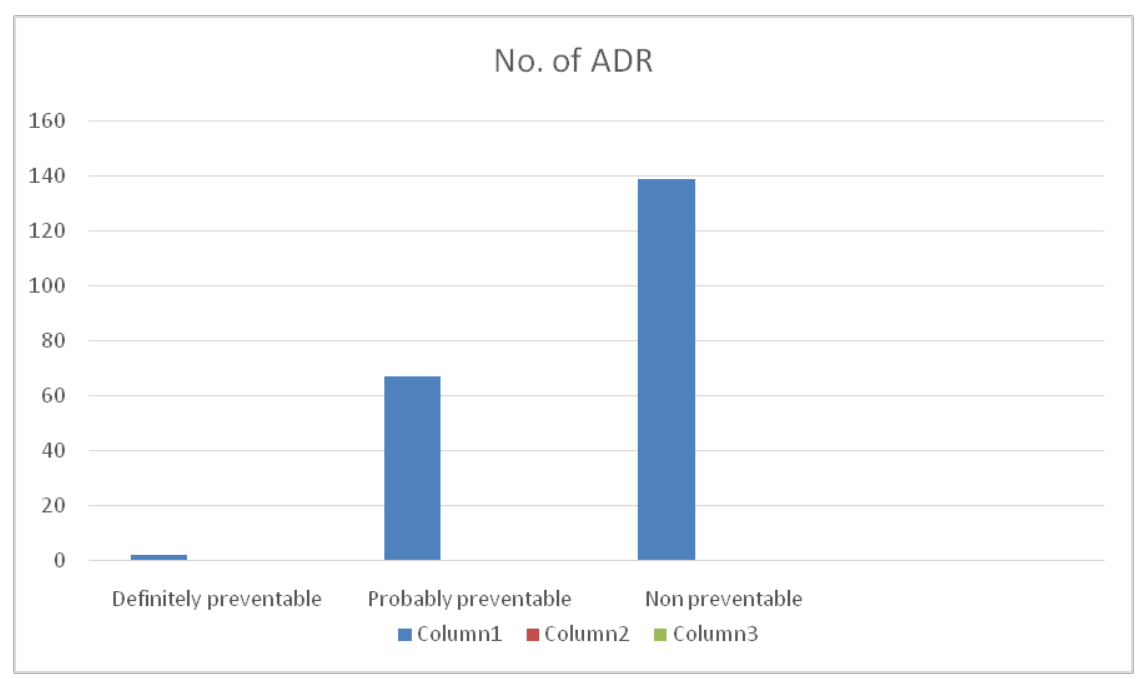

Fig. 3: Preventability assessment of ADRs by schumock and thronton scale

\section{DISCUSSION}

DR-TB is difficult to treat day by day as it requires long-term exposure and is associated with greater toxicity effects. ADR associated with these drugs may further complicate the picture and is a main challenging factor. The present observational study has evaluated the pattern and frequency of adverse drug reactions and assessed their severity, causality, and preventability in patients receiving treatment for DR-TB. The demographic characteristics of patients were compared to previous studies. In most reports' females are at high risk for DR-TB but in the present study males and females have equal chances of getting DR-TB.

In table 1 the DR-TB patients were classified into 5 categories (age group was classified according to study: Population-Based Drug Resistance Surveillance of Multidrug-Resistant Tuberculosis in Taiwan, 2007-2014) according to their age. More patients were seen in the age group 46-65 of male categories and 26-45 age group of female categories. By comparing the study conducted by Mehari $\mathrm{K} e t$ al. that claims MDR TB to be more prevalent among the age group 15-44 ie. within the productive age group, this study witnessed more MDR-TB cases outside this range [10].

More males than females suffer from tuberculosis worldwide. This study also indicates that there were more male cases with DR TB than females and therefore, males have higher incidences of adverse events than female patients. This is because men were vulnerable to ADR due to economic responsibility and environmental exposure to resistant strain and also as they recorded more addictions towards smoking, alcohol intake, which results in the weakening of immunity [11].

In the present study, a total number of 208 ADRs were observed in 91 patients, as more than one ADR has been observed in 41 patients. The occurrence of ADR (table 1) associated with gastritis being the most common is persistent with other reports too [12]. Even though gastritis being the most predominant ADR in this study, the occurrence is lower as compared to other existing studies (12.98\%), which might be due to under-reporting by patients and as they rely on OTC medications for symptomatic relief [6]. These disturbances are most pronounced after treatment with ethambutol and PAS, even though all drugs cause a similar effect to an extent. Most GI side effects can be managed without stopping the drug by decreasing the dose, dividing the dose, or using antiemetics. If the GI symptoms were not severe, additional $\mathrm{H} 2$ receptor blockers or antiemetic agents were incorporated into the regimen [12].

Ototoxicity was the second most common ADR and the increased rate of ototoxicity may be due to higher dose and long-term exposure (up to $12 \mathrm{mo}$ ). The study conducted by Shibeshi W et al. has proved the association of ototoxicity by using kanamycin and other aminoglycosides. Kanamycin is primarily cochleo-toxic; however, long-term use may result in permanent hearing loss and damage to the vestibular apparatus, which leads to dizziness, ataxia, or nystagmus. The mechanism underlying is, on chronic administration of aminoglycosides generates free radicals within the inner ear, with subsequent permanent damage to sensory cells and neurons, resulting in permanent hearing loss. Drug-induced ototoxicity can be triggered by several conditions such as smoking and alcohol use, prolonged duration of treatment, malnutrition, aging, some bacterial infections, and genetic factors [13].

$\mathrm{Km}$ is the most ADR-causing drug that induces ototoxicity, nephrotoxicity, and vertigo as they were used for a longer duration. The action mainly taken for Kanamycin-induced ototoxicity was the withdrawal of $\mathrm{Km}$, which was replaced with PAS. Ototoxicity was the major ADR that requires drug withdrawal. In contrary to other studies(Amin $\mathrm{S}$ et al.) the second and third most common causal agent was cycloserine and ethambutol in this present study [5]. Severe psychiatric symptoms and psychosis, including hallucinations, anxiety, depression, euphoria, behavioral disorders, and suicidal ideation or attempts, have been reported to occur in individuals receiving Cs [14]. Thus, Cs-associated neurotoxicity is likely due to diminished central nervous system production of gamma-aminobutyric acid caused by inhibition of glutamic decarboxylase [15]. The study by Jaramillo E reports that if psychiatric disturbances occur in patients receiving cycloserine, the drug was supposed to be stopped and substituted with PAS leading to rapid recovery of mental status and with no recurring symptoms [16]. Pyrazinamide and ethambutol have been associated to cause an increase in uric acid levels. Severe hyperuricemia can lead to renal failure. Hence, uric acid level measurement should be done particularly in patients with pre-existing conditions [17]. Hepatotoxicity was the most common ADR by anti-TB drugs and this study does not report any cases. The drug-induced hepatotoxicity is highly variable and ranges from an asymptomatic elevation of liver enzymes into fulminant hepatic failure. It is also important that TB itself can invade the liver and result in abnormal liver function [12]. When there is hepatotoxicity associated with the use of a drug, the drug leading to hepatotoxicity is suspended until liver function tests return to normal limits. Gradually introducing the drugs by administering them in increasing numbers and dosages is recommended as per guidelines. The drugs most commonly associated with hepatotoxicity like Isoniazid, should be used cautiously. Pyrazinamide causes arthralgia, arthritis, and gout. Symptoms of pyrazinamide-induced arthralgia had been reduced and treated with NSAIDs, although pyrazinamide should be withdrawn if acute gout attacks occur.[12]In our present study ethionamide can cause gynecomastia and hypothyroidism. It can cause hypothyroidism by inhibiting thyroid hormone synthesis through a mechanism of iodine organification inhibition [18].

To establish a causal relationship between a drug and an adverse event, it is necessary to carry out a causality assessment. In the 
present study, a causality assessment was done using Naranjo's and WHO-UMC algorithms.

Naranjo's scale was based on the points given for each question which comprise of ten questions that are answered 'Yes', 'No' or 'Do not Know'. After totaling the points, they were categorized into definite ( $\geq 9$ ), probable (5-8), possible (1-4) and unlikely $\leqslant 0$ ) [19] Majority of the ADR belongs to the probable $(67.8 \%)$ category while $29.32 \%$ were possible reactions (table no 3 ) which is contrary to the study conducted by Shinde MP et al. [6].

In the WHO-UMC scale for assessing ADRs categories like certain, probable, possible, unlikely, unclassified, and unclassifiable were considered. Based on that, $44 \%$ were probable, $36 \%$ possible reaction, $17 \%$ were certain and $3 \%$ were unlikely, which is similar to other studies conducted by BJ M K et al. [19].

For the proper management of ADR, it is better to study the severity of ADR. Modified Hartwig and Seigel scale was used to assess the severity which categorizes the ADR into mild, moderate, and severe. In the present study majority of the ADR $(23.07 \%)$ were moderate level $4 \mathrm{~b}$ and $17.3 \%$ were mild (table 4 ), which is similar to the study conducted by Shindhe MP et al. [6].

Schumock and Throton scale was established for assessing the preventability of ADR. Using this scale, $66.82 \%$ were classified as non-preventable, $32.2 \%$ were probably preventable and $0.96 \%$ were definitely preventable (fig. 3).

Due to its retrospective nature, we have missed the opportunity of direct patient interaction and thus, the details of ADR were obtained only from the medical records of the patients. Many of the ADRs were under-reported and it has influenced this study results and the study could not correlate the laboratory values with the ADR.

\section{CONCLUSION}

ADR stands to be a great de-motivator for the patients which results in an overall decrease in adherence to treatment. Therefore, there is an urgent need for regular monitoring, timely reporting, and adequate management of ADR. Gastritis is the most common ADR followed by ototoxicity and vomiting. Kanamycin and cycloserine are the major culprit drugs that require drug withdrawal and replacement with PAS. As the number of drugs increase, a probable increase in the ADRs is also observed; thus this study concludes that there is an urgent need for proper monitoring and management of ADR to increase patient compliance.

\section{LIMITATIONS}

Our study being retrospective, has missed the opportunity to obtain direct patient information and incomplete follow-up details. Some of the ADRs were under-reported because of, lack of awareness about the ADR among patients. Only significant ADR has been recorded.

\section{AUTHORSHIP}

All authors contributed equally to the study and the article.

\section{ACKNOWLEDGMENT}

We express our gratitude towards state and district Tuberculosis coordinators for their permission, support, and assistance given during the project period.

\section{FUNDING}

No funding was received by the authors.

\section{AUTHORS CONTRIBUTIONS}

All the authors have contributed equally.

\section{CONFLICT OF INTERESTS}

The authors declare that there is no conflict of interest.

\section{REFERENCES}

1. Kurz SG, Furin JJ, Bark CM. Drug-resistant tuberculosis: challenges and progress. Infectious Disease Clin 2016;30:509-22.

2. World Health Organization. Stop TB Initiative (World Health Organization). Treatment of tuberculosis: guidelines. World Health Organization; 2010.

3. Nusrath Unissa A, Hanna LE, Swaminathan S. A note on derivatives of isoniazid, Rifampicin, and pyrazinamide showing activity against resistant Mycobacterium tuberculosis. Chem Biol Drug Des 2016;87:537-50.

4. Prasad R, Singh A, Gupta N. Adverse drug reactions in tuberculosis and management. Indian J Tuberc 2019;66:520-32.

5. Amin S, Mishra V, Mira D, Rajesh S. Pattern of adverse drug reactions and its potential impact on drug-resistant tuberculosis patients at a tertiary care teaching hospital in Western India. Clin J Pharmacol Pharmacother 2018;1:15-20.

6. Shinde MP, Halasawadekar NR, Ramanand SI, Pore SM, Ramanand JB, Patil PT, et al. A study of adverse drug reactions in patients receiving treatment for multi-drug resistant tuberculosis. Int J Basic Clin Pharmacol 2017;34:354-8.

7. Isaakidis P, Varghese B, Mansoor H, Cox HS, Ladomirska J, Saranchuk P, et al. Adverse events among HIV/MDR-TB coinfected patients receiving antiretroviral and second-line antiTB treatment in Mumbai, India. PloS One 2012;11:e40781.

8. Gualano G, Mencarini P, Musso M, Mosti S, Santangelo L, Murachelli $\mathrm{S}$, et al. Putting in harm to cure: drug-related adverse events do not affect the outcome of patients receiving treatment for multidrug-resistant tuberculosis. Experience from a tertiary hospital in Italy. PloS One 2019;14:e0212948.

9. Hire R, Kale AS, Dakhale GN, Gaikwad N. A prospective, observational study of adverse reactions to drug regimen for multi-drug resistant pulmonary tuberculosis in central India. Mediterranean J Hematol Infectious Diseases 2014;6:e2014061.

10. Mehari K, Asmelash T, Hailekiros H, Wubayehu T, Godefay $\mathrm{H}$ Araya $\mathrm{T}$, et al. Prevalence and factors associated with multidrug-resistant tuberculosis (MDR-TB) among presumptive MDR-TB patients in tigray region, Northern Ethiopia. Canadian J Inf Diseases Med Microbiol 2019;1-8. https://doi.org/10.1155/2019/2923549.

11. Bistline KL. Does the inclusion of the cost and burden of adverse drug reactions associated with drug-resistant TB treatment affect the incremental cost-effectiveness of new treatment regimens? A case study from the introduction of bedaquiline in South Africa National TB Programme (Doctoral dissertation, University of Cape Town); 2018.

12. Yang TW, Park HO, Jang HN, Yang JH, Kim SH, Moon SH, et al. Side effects associated with the treatment of multidrugresistant tuberculosis at a tuberculosis referral hospital in South Korea: a retrospective study. Medicine 2017;96:e7482.

13. Shibeshi W, Sheth AN, Admasu A, Berha AB, Negash Z, Yimer G. Nephrotoxicity and ototoxic symptoms of injectable second-line anti-tubercular drugs among patients treated for MDR-TB in Ethiopia: a retrospective cohort study. BMC Pharmacol Toxicol 2019;20:31.

14. Kennedy NA, Oluwaseun A, Denis AD, Chukwuemeka SP. Cycloserine induced-psychosis in a 22-year old male pharmacy student: a case report. Am J Psychiatry Neurosci 2016;4:1-4.

15. Dere E, Zlomuzica A, Silva MD, Ruocco LA, Sadile AG, Huston JP. Neuronal histamine and the interplay of memory, reinforcement and emotions. Behavioural Brain Res 2010;215:209-20.

16. Jaramillo E. Guidelines for the programmatic management of drug-resistant tuberculosis. World Health Organization; 2008.

17. Pham AQ, Doan A, Andersen M. Pyrazinamide-induced hyperuricemia. Pharm Ther 2014;39:695-715.

18. Drucker D, Eggo MC, Salit IE, Burrow GN. Ethionamide-lnduced goitrous hypothyroidism. Annals Int Med 1984;100:837-9.

19. BJ MK, Mathew S, Ramesh S, Hymavathi R, Srikanth MS. Causality assessment of adverse drug reactions in tuberculosis patients who are on directly observed treatment short-course strategy in mysore district. Indian J Pharm Practice 2013;6:22-6. 